\title{
ESPECIALIZAÇÃO EM EDUCAÇÃO AMBIENTAL NO ENSINO À DISTÂNCIA (EaD) DA UFSM: UMA ANÁLISE CRÍTICA DA SELEÇÃO À FORMAÇÃO
}

\author{
Carla da Rosa Lopes ${ }^{1}$, Jorge Orlando Cuéllar Noguera ${ }^{2}$ \\ ${ }^{1}$ Especialista em Educação Ambiental pela UFSM. \\ ${ }^{2}$ (Orientador) Prof. do Curso de Especialização em Educação Ambiental da UFSM. \\ carlarosal@msn.com,jocunoguera@hotmail.com
}

\section{RESUMO}

A Universidade Federal de Santa Maria-RS, é uma Instituição Pública de Ensino Superior que visa à qualificação profissional dos alunos a partir de um ensino-aprendizagem com caráter científico e tecnológico de qualidade. Pensando em democratizar este ensino, a UFSM sempre busca a implantação de novos cursos. Assim, visando uma diminuição das diferenças socioculturais, a UFSM através dos programas de Educação a Distância desenvolvidos pela UAB (Universidade Aberta do Brasil), implementa o Curso de Especialização em Educação Ambiental à Distância (EaD). O objetivo desta monografia é identificar o perfil dos candidatos e dos alunos formados deste curso. O curso de Especialização em Educação Ambiental em EaD foi implementado pela UFSM no ano de 2008, alcançando o total de 5 (cinco) pólos ativados no Estado do Rio Grande do Sul no ano de 2009. Estes pólos encontram-se nos municípios de Agudo, Cacequi, Panambi, São Sepé e Sapiranga. Analisou-se o perfil dos candidatos ao curso, dos alunos formados e, de alguns desistentes. Utilizando uma metodologia quantificada de dados e informações exteriorizadas pelos referidos estudantes, através de questionários.

Palavras-Chave: Candidatos; Seleção; Perfil acadêmico; Educação ambiental; Ensino à distância.

\section{Abstract}

The Universidade Federal de Santa Maria-RS, is a Public Institution of Higher Education which aims to professional qualifications of students from a teaching-learning with a scientific and technological quality. Thinking about this democratize education, UFSM always seeks the implementation of new courses. Thus, seeking a reduction in social and cultural differences, UFSM through Distance Education programs developed by UAB (Open University of Brazil), implements the Specialization Course in Environmental Education for Distance Learning (ODL). The purpose of this monograph is to identify the profile of candidates and graduates of this course. The Specialization Course in Environmental Education in UFSM EaD was implemented by the year 2008, reaching a total of five (5) poles in the activated state of Rio Grande do Sul in 2009. These poles are in the municipalities of Agudo, Cacequi, Panambi, Sao Sepe and Sapiranga. We analyzed the profile of candidates for the course, students and graduates, some dropouts. Using a 


\section{Monografias Ambientais}

REMOA

(Revista Eletrônica do Curso de Especialização em Educação Ambiental da UFSM)

methodology of quantified data and information externalized by these students through questionnaires.

Keywords: Candidates; Selection; Ecademic profile; environmental education; Distance learning.

\section{INTRODUÇÃO}

O Curso de Especialização em Educação Ambiental inseriu-se na modalidade EaD no ano de 2008, alcançando já no ano de 2009, um total de 05 pólos ativados no Estado do Rio Grande do Sul. Sendo encontrados nos municípios de:

- $\quad$ Agudo (como Pólo de Apoio Presencial ao Ensino Superior);

- $\quad$ Cacequi (como Pólo UAB), Panambi (como Pólo Presencial UAB);

- São Sepé (como Pólo de Educação Superior Sepé Tiarajú - UAB) e,

- $\quad$ Sapiranga (como Pólo Universitário de Educação à Distância).

Vale lembrar que o ensino com propósito de qualificar e profissionalizar o indivíduo se faz desde longa data, em modalidade à distância diferenciada, pois, não havia se pensado em ensino pela internet. $O$ ensino na modalidade em educação à distância, permitiu que muitos estudantes ou profissionais, ainda no século $X X$, pudessem adquirir conhecimentos mais específicos, além de terminarem os seus estudos, sempre descartando a observância relativa à idade, profissão e localidade dos seus interessados.

No decorrer da história e com a evolução do homem, somadas à evolução tecnológica, política, econômica, social e cultural, houve a necessidade de novos métodos de ensinoaprendizagem. Atualmente, a partir da utilização de computadores e da internet tornou-se possível a realidade de um novo sistema de ensino à distância, supra referido, dentre muitos outros que não foram citados.

Para que a pesquisa se considere em sua totalidade, serão analisadas algumas perspectivas, tanto em relação aos estudantes, como aos professores e, inclusive com relação aos tutores do referido curso. E, não menos importante, será realizada uma investigação sobre como é realizado o curso, sua legislação e, como se dá a estrutura dessa especialização.

O objetivo geral deste estudo foi realizar uma análise sobre o perfil dos interessados no CPG em Educação Ambiental na modalidade de EaD da UFSM, na busca de identificar o perfil dos estudantes egressos na Especialização, bem como dos concluintes deste CPG. E, a partir de tal análise, busca-se conhecer o curso e seus interessados, sempre visando um melhoramento do sistema deste CPG.

Demonstra-se, então, os objetivos específicos desta pesquisa:

- Conhecer o perfil dos candidatos e dos formados nesta Especialização, desvendando o que esperam do curso;

- Buscar identificar, nesses estudantes e acadêmicos, o(s) motivo(s) que os levaram a buscar a formação especializada em Educação Ambiental;

- $\quad$ Analisar os alunos que, no decorrer do período, desistiram desta CPG;

- $\quad E$, analisar as monografias realizadas e defendidas até o presente momento.

Assim, este estudo se justifica na busca pelo conhecimento sobre o curso, principalmente no que consiste à UFSM, bem como demonstrar como está disposta a estrutura do curso (suporte 


\section{Monografias Ambientais}

REMOA

(Revista Eletrônica do Curso de Especialização em Educação Ambiental da UFSM)

técnico), pois, trata-se de um ensino-aprendizagem que democratizou a educação ambiental na cidade de Santa Maria/RS, dentre outras, e que pelos conteúdos que aborda e discute, permite a busca da democratização do ambiente como um todo, bem como da responsabilidade social e moral do ser humano enquanto indivíduo.

O presente estudo está apresentado em cinco capítulos distintos, onde estarão transcritas as idéias fundamentais em cada um de seus conteúdos, demonstrando-se a finalidade, os resultados e, dentre outros marcos, as considerações finais.

No primeiro capítulo, será exposta uma idéia introdutória, aludindo sobre a educação à distância, bem como serão trabalhados os objetivos do trabalho, sua justificativa e a metodologia de pesquisa.

As abordagens do segundo capítulo se reportam ao estudo propriamente dito. Neste sentido, serão descritas as normatizações que regularizam esse curso de especialização em EaD e, os regimentos legais relativos ao curso.

Contudo, no capítulo terceiro, serão esclarecidos os métodos utilizados para a realização da presente pesquisa, bem como serão trabalhadas algumas possibilidades de resultados.

No capítulo quarto, serão discutidos os resultados obtidos a partir dos métodos de pesquisa supracitados. Serão apresentados os resultados das análises decorrentes dos questionários respondidos pelos alunos, professores e tutores desta especialização, assim como será realizada uma avaliação de como estes resultados poderão interferir no CPG de educação ambiental em EaD.

E, por fim, no quinto capítulo ficarão elencadas as conclusões desta monografia, avaliando se o estudo atingiu suas expectativas e se os resultados satisfazem, de qualquer sorte.

Após, essa exposição, cabe partir para a próxima etapa do presente estudo, visando sanar os seus objetivos.

\section{REVISÃO BIBLIOGRÁFICA}

Iniciar um trabalho que trate das relações existentes com base na educação ambiental, no mundo contemporâneo, torna-se um tanto complicado. Nesse sentido, elucida-se que a sociedade encara grandes desafios. Nada obsta que se fale nas crises que a sociedade enfrenta na atualidade. Há quem chame de crises sociais ou civis, por que envolvem o homem, na sua individualidade ou porque envolvem o homem como um ser de vida social e, portanto, moral. Mas, independente do nome que se dê a estes desafios, as crises existem e tem âmbito global.

Cabe lembrar que, as crises enfrentadas são ainda de cunho cultural, ético e moral, sendo crises de desenvolvimento humano, pois, interferem de qualquer modo na vida das pessoas. Ainda há a crise econômica, a crise tecnológica e, por que não se reportar a crise política e, à globalização.

De qualquer sorte, percebe-se no decorrer de toda a história da humanidade que as grandes lutas surgiram a partir de grandes crises, assim como as grandes conquistas humanas.

A educação é um ponto chave, quando se trata dessas questões, pois desde que o mundo é mundo, reporta-se à educação visualizando seus dois lados, porém importante se faz lembrar de que também há a crise da educação. Relevante essa lembrança! 


\section{Monografias Ambientais}

Há que se ter em mente de que a educação ${ }^{3}$ é solução para grandes dos muitos problemas enfrentados pela sociedade. Também, não se pode deixar de lado o fato de que a educação encara situações difíceis, pois ainda existe a falta ou dificuldade de acesso à informação, à escola. E isso ocorre na mesma proporção em que a sociedade enfrenta a falta de professores/educadores nas escolas e, até mesmo a falta de escolas em determinadas localidades. Esse não é um mundo distante, infelizmente é preciso encará-lo.

Dentro desse contexto, há que se falar em educação ambiental. A educação em relação ao ambiente, que precisa e permite o diálogo entre os indivíduos, das mais variadas áreas do conhecimento para estabelecer, aprimorar o saber ambiental. Mas, não é só isso!

Assim, o estudo ora apresentado, pode ser considerado como uma pesquisa que tratará da educação ambiental sob o aspecto daqueles que buscam esse conhecimento, daqueles que tem por vontade conhecer, entender e, se possível, após a aquisição desses saberes, buscarem transmitir os ensinamentos ao mais elevado número de pessoas possível. Significa dizer que além do conhecimento é preciso ter atitude, a partir de uma mudança de comportamentos e, mudanças nos conceitos sobre as formas de vida e de vivê-la ${ }^{4}$.

É a partir do saber, do conhecer (da educação) que será possível a mudança de atitude de todo o ser humano. Pois, é isso que a educação ambiental sugere. Precisa-se do domínio e conhecimento, das limitações e necessidades da vida no ambiente natural, na sua totalidade, para a partir daí buscar maiores transformações do homem individual, deste em sociedade e de toda a vida terrestre.

Desse modo, é preciso valorizar a educação, pois é através dela que pode-se investir ${ }^{5}$ na educação ambiental, a qual forma educadores e educadoras. Assim, tem-se a Universidade Federal de Santa Maria (UFSM), que oportuniza esse conhecimento aos seus alunos do Curso de Pós-Graduação (CPG), em nível de Especialização, em educação ambiental.

Neste momento, cabe apresentar a UFSM, ou ainda, sob a forma de como esta Instituição de Ensino Superior (IES) cria e mantém seus cursos e sua qualidade de ensino. A UFSM situa-se no Estado do Rio Grande do Sul e, é uma Instituição Pública de Ensino Superior que visa à qualificação profissional de seus alunos a partir de um ensino-aprendizagem com caráter científico e tecnológico de qualidade.

Pensando em democratizar este ensino, a UFSM, sempre buscou a implantação de novos cursos. Atualmente, esta Instituição possui 10 cursos de graduação na modalidade de Educação à Distância (EaD).

Importante referir que os Pólos da Universidade Aberta do Brasil (UAB) e UFSM, engajados na EaD, tanto em nível de graduação como de pós-graduação, estão distribuídos em 27 cidades dentro do Estado do Rio Grande do Sul.

Antes de serem realizadas novas elucidações, impreterível se faz a referência sobre a Educação e algumas de suas normatizações mais relevantes. Nesse sentido, cabe mencionar o artigo 6ㅇ da Constituição Federal de 1988 (CF/1988), (TOLEDO, 2010, p.11), neste dispositivo legal estão expostos alguns dos direitos sociais, onde se insere a educação.

\footnotetext{
${ }^{3}$ Neste contexto, refere-se à educação no seu sentido mais amplo. Quer-se dizer sobre uma educação moral, ética, cidadã, ambiental, social, política, etc.

${ }^{4}$ Neste momento, busca-se demonstrar a importância de novos conceitos, estabelecendo padrões de mentalidades e atitudes. Busca-se, na verdade, introduzir a idéia de que é necessário estabelecer novos paradigmas, a partir de novos juízos de valor.

${ }^{5}$ E por que não dizer: Incentivar... Pois, a Educação Ambiental precisa ser instigada, incentivada, (re)avaliada, investigada e (re)criada. Para que hajam estas possibilidades é preciso pretensão, envolvimento, ousadia e muito interesse social, pois, sem este as dificuldades permanecerão intactas, imutáveis, intocáveis, etc.
} 


\section{Monografias Ambientais}

REMOA

(Revista Eletrônica do Curso de Especialização em Educação Ambiental da UFSM)

A Educação é um direito social do indivíduo e, conforme Pedro Lenza apud Oliveira (2008), quando explica as características dos direitos fundamentais:

Arrola, ainda, as seguintes características dos direitos fundamentais: I - imprescritibilidade (não se perdem pelo seu não-uso), II - irrenunciabilidade, III - inalienabilidade, IV concorrência (possibilidade de acumular), V - limitabilidade (os direitos não são absolutos e sim relativos), VI - universalidade (destinam-se a todos os seres humanos) e VII historicidade (decorre de conquistas revolucionárias). (OLIVEIRA, 2008, p.52)

Os direitos e garantias fundamentais contidos na Constituição Federal de 1988 (2010) dividem-se em direitos individuais, coletivos, políticos, sociais, entre outros. Assim sendo, a educação é um direito fundamental, por isso, imprescritível, universal, irrenunciável do indivíduo.

Mantendo essa noção, outros dispositivos constitucionais se referem no sentido supra, a exemplo dos artigos 205, caput, 206 e 207. Desta feita, faz-se referência à educação em EaD e, neste aspecto, importante reportar ao pensamento de Paulo Freire, nas palavras de SCOCUGLIA (1999, p.23), quando indaga que:

\footnotetext{
Entendemos que se suas propostas político-pedagógicas não permitissem novas descobertas e novas experimentações, como partes intrínsecas da sua própria concretude, existência e disseminação, tornar-se-iam inertes e enrijecidas. Suas propostas foram feitas para serem recriadas, conforme o cotidiano, o imaginário, os interesses e os valores, conforme as condições de vida de seus participantes - educando e educadores.
}

Em outras palavras, entende-se que Scocuglia (1999) quis demonstrar que Paulo Freire, de certa forma, já antecipava-se quanto à modalidades de ensinos, pois tratava da questão de novos métodos educacionais de modo singelo, explorando as futuras (e, por que não dizer, atuais) necessidades dos estudantes e dos educadores, visando as necessidades de seus entes (educandos e educadores).

Confirmando essa idéia, o artigo 80 da Lei Federal de no 9.394 de 1996, que instituiu a EaD no País, estabelece que "o Poder Público incentivará o desenvolvimento e a veiculação de programas de ensino a distância, em todos os níveis e modalidades de ensino e de educação continuada".

O Estado do Rio Grande do Sul está incluído na lista dos 10 Estados que seguem legislação própria, assim como Santa Catarina e Paraná, obtendo como normatização primeira, a Resolução 262 de 03 de outubro de 2001, que estabelece parâmetros regulamentares à EaD, com supremacia, na UFSM.

O curso de Educação Ambiental em EaD possui um Regimento Interno, onde estabelece normas que regularizam o andamento do curso, desde a entrada do estudante, que deverá ser realizada por edital de seleção, até o término de suas atividades no curso, estando vinculado ao Centro de Ciências Rurais da UFSM, conforme a Resolução de no 017 de 2000 (Projeto Pedagógico).

Outra norma estabelecida está no que diz respeito, ao Decreto 5.622 de dezembro de 2005. Ainda há a Lei de no 6.938 de agosto de 1981, que trata da Política Nacional do Meio Ambiente (PNMA), onde em seu artigo 4으, inciso $\mathrm{V}$, que esta política tem por objetivo (dentre 


\section{Monografias Ambientais}

REMOA

(Revista Eletrônica do Curso de Especialização em Educação Ambiental da UFSM)

muitos outros), "à difusão de tecnologias de manejo do meio ambiente, à divulgação de dados e informações ambientais e à formação de uma consciência pública sobre a necessidade de preservação da qualidade ambiental e do equilíbrio ecológico". ${ }^{6}$

Para que a Educação Ambiental possa ser, de modo permanente e confiável, absorvida ou adquirida pelos diversos públicos, importante é que seus conceitos e idéias sejam expostos por especialistas, pessoas qualificadas para tal transmissão de conhecimentos.

Em mesmo artigo, porém, no §4으, está definido que as avaliações realizadas pela CAPES, no que diz respeito aos cursos de pós-graduações em EaD, deverão seguir os mesmos critérios de qualidade, na formação dos estudantes, dos cursos executados em seu ensino presencial.

Sendo assim, o Plano Pedagógico deste CPG, aborda sobre os princípios, conceitos, forma de trabalho a ser realizado entre o corpo docente e discente, bem como se refere a estrutura que a UFSM oportuniza para a concretização deste curso.

Como perfil do profissional em EA, tem-se que, este curso busca inserir na sociedade, dentro da UFSM, grupos de pessoas qualificadas para trabalharem com a Educação Ambiental em todos os âmbitos de conhecimento, agindo no campo da educação formal e/ou informal.

Assim, faz-se relevante apresentar o perfil do especialista em EA, conforme o Sistema de Educação Ambiental em EaD, diz respeito ao seguinte:

O profissional com título de especialista em educação ambiental terá uma visão global e interdisciplinar do meio ambiente. Ele deverá ser um agente multiplicador na análise dos problemas ambientais, buscando soluções para os problemas ambientais no âmbito da educação formal e informal, englobando a técnica e a teoria pedagógica. ${ }^{7}$

Então, o perfil do estudante em Educação Ambiental deve ser de alguém que consegue visualizar as condições atuais do meio ambiente, trabalhando de modo interdisciplinar, de modo contínuo, transmitindo seus conhecimentos a todos os públicos de maneira racional e coerente, utilizando-se dos conhecimentos que tem para aplicá-los em sua vida particular.

Conforme o Projeto Pedagógico, os docentes são responsáveis por algumas ações, diretamente ligadas com a área de concentração do CPG, como:

- No que diz respeito a área de Educação, Sociedade e Cultura, os docentes transmitiram conhecimentos sobre sociedade, com métodos e linguagens próprias, visando orientar atividades humanas;

- Na área de Problemas Ambientais, onde os docentes estudaram sobre a natureza e suas diversas apresentações e formas;

- E, por fim, trata-se da área de Práticas Ambientais, onde serão trabalhados de modo conjunto, os conhecimentos práticos e teóricos.

O perfil docente do CPG em Educação Ambiental em EaD diz respeito a 04 professoras e 11 professores. Destas 04 professoras, 03 são envolvidas na linha de Educação, Sociedade e Cultura, restando apenas 01 professora que trabalha com as questões das problemáticas ambientais.

Dos 11 professores, 06 trabalham com a linha de Educação, Sociedade e Cultura e, 05 trabalham com as problemáticas ambientais.

\footnotetext{
${ }^{6}$ Lei de no 6938 de agosto de 1981, Política Nacional do Meio Ambiente. Disponível em: <http://www.jurisambiente.com.br/ambiente/lei3.htm> Acesso em: 16 set. 2010.

${ }^{7}$ Perfil do Especialista em Educação Ambiental em EAD da UFSM. Disponível em: <http://www.ufsm.br/educacaoambientaladistancia/>. Acesso em: 3 set. 2010.
} 


\section{Monografias Ambientais}

REMOA

(Revista Eletrônica do Curso de Especialização em Educação Ambiental da UFSM)

Todos os 15 professores do CPG possuem titulação de Doutorado e, a grande maioria deles já realizou ou, ainda, realiza atividades como Professor/tutor no Sistema Moodle/EaD/UAB.

Para iniciar as questões relativas aos tutores deste CPG, faz-se necessário elucidar que os tutores são auxiliares dos professores nas disciplinas em que atuam e, têm a função de acompanhar os alunos, orientando-os em suas atividades.

Existem dois tipos de tutores, sendo o tutor à distância e o tutor presencial. Este deverá estar presente, com assiduidade, no pólo em que atuará. Ambos são selecionados conforme o número de alunos de cada pólo e disciplinas, sendo estabelecidos dois tutores presenciais por pólo. Devendo o aluno estar matriculado regularmente na UFSM, em curso de graduação ou de Especialização em Educação Ambiental.

\section{MATERIAL E MÉTODOS}

O material primordial para a elaboração deste estudo está em questionários aplicados aos estudantes candidatos e formados, do primeiro ano do CPG, que serão analisados posteriormente. E a metodologia aplicada será a partir de análises sob os aspectos quantitativos e qualitativos, buscando formatar uma estatística com base nos dados fornecidos pelos alunos.

Os materiais utilizados serão CD's relativos ao SEED/MEC; legislações que abrangem a educação à distância, utilizando-se da interpretação dedutiva-hermenêutica, nesse sentido; questionários, propriamente ditos, donde apresentarão vários aspectos, objetivos e subjetivos, para a merecida análise de realidade para a construção desta pesquisa, e bibliografias essenciais para a elaboração desta pesquisa e, materiais de apoio e bibliografias complementares das idéias fundamentais deste estudo.

Este trabalho monográfico possui como metodologia a utilização de técnicas descritivas, técnicas analíticas de pesquisa, e técnicas quantitativas e qualitativas..

\section{RESULTADOS E DISCUSSÃO}

A partir das propostas de estudos para a elaboração desta pesquisa, chegou-se a alguns resultados, dos quais passam a ser expostos, neste contexto.

Em uma análise generalizada, ou seja, serão expostos neste estudo apenas os dados totais relativos aos cinco pólos pesquisados. Assim, chegou-se aos resultados, abaixo:

Foram entrevistados 191 estudantes, resultando em 134 mulheres e 58 homens entrevistados.

Fez-se referência à zona de residência dos entrevistados, resultando em 7 estudantes que residem em localidades rurais e, os demais 184 residem em zona urbana.

Os estudantes que exercem atividades remuneradas ou, em outras palavras, trabalham, totalizam em 175 profissionais, que buscaram a realização do curso. E, observou-se que 17 estudantes não trabalham, sendo totalmente dependentes de seus familiares.

Todos os 191 entrevistados possuem acesso ao computador, e que neste caso, subdividese em 92 estudantes que possuem computador em suas residências, outros 87 possuem computador em suas casas e no ambiente de trabalho. Mais 3 afirmam que possuem esse acesso em casa e na universidade a qual são vinculados e, apenas 1 indicou que possui computador em sua residência e freqüenta um ciber. 


\section{Monografias Ambientais}

Dos entrevistados, 3 estudantes têm computador apenas no ambiente profissional, enquanto que 5 possuem computador em casa, no trabalho e na universidade em que estudam.

O que mais se mostra interessante é o fato de que, hoje em dia, com tantos acessos facilitados ao sistema informatizado, ainda existem locais de trabalho que não disponibilizam computadores para seus funcionários. Será? Ainda, por outro lado, a que se levar em consideração os tipos de atividades profissionais realizadas pelos entrevistados..

Neste contexto, analisaram-se os turnos que esses estudantes podem disponibilizar para seus estudos. Nota-se que apenas um estudante disponibiliza sua manhã para seus estudos, contra 5 que disponibilizam o período da tarde. Outros 95 possuem as noites para estudarem, enquanto que 25 estudam de manhã e noite.

São disponibilizadas as tarde e noites por 34 estudantes, face a 3 indivíduos que estudam de manhã e de tarde. $E$, ainda, totalizam 20 estudantes que disponibilizam seus três turnos para os estudos.

Observou-se que os estudantes, candidatos ao curso, ou mesmo, aqueles que se formaram, dedicaram a maior parte de seu tempo na realização de atividades acadêmicas. Neste contexto, verifique os dados seguintes.

No que compete a disposição de dias da semana dedicados às atividades acadêmicas, resultam em 7 estudantes que estudam em um único dia, sendo 13 alunos que dispõem de 2 dias de estudos, contra 31 estudantes que estudam em 3 dias da semana.

Ainda, verificou-se que 41 estudantes têm 5 dias livres, enquanto que 22 estudantes possuem 6 dias livres e, por fim, 43 estudantes disponibilizam de 7 dias de estudos. E, finalizando este primeiro momento de análise dos resultados das entrevistas aos estudantes, observou-se que 56 estudantes residiam na cidade-pólo do CPG em EaD, enquanto que 135 estudantes afirmaram que não residiam na cidade-pólo do curso.

Neste momento, importante referir-se às situações de desistência ocorridas nos Pólos de Panambi/RS e São Sepé/RS, pois resultaram em 19 alunos que se retiraram do curso.

No Pólo de Panambi/RS, seis alunos desistiram do curso pelos motivos expostos:

Quatro estudantes alegaram a falta de tempo para as atividades diárias, pois, não conseguiram conciliar estudos, trabalhos e família. Um aluno(a) alegou grande dificuldade com relação ao acesso à internet, pois, reside longe do Pólo de EaD e, outro aluno(a) apresentou sua dificuldade de acesso ao Pólo EaD, pois precisou residir em um Município distante do Pólo.

No que diz respeito ao Pólo de São Sepé, totalizam-se 13 desistências, pelos motivos de que:

Sete alunos(as) não freqüentaram o curso durante o seu II Semestre; um aluno(a) alegou problemas particulares; um aluno(a) reclamou falta de flexibilidade nas entregas das atividades/avaliações das disciplinas do curso e, quatro alunos(as) alegaram falta de tempo para as atividades diárias, pois não conseguiram conciliar estudos, trabalho e família.

Os resultados foram alcançados devido aos questionários entregues pelos estudantes, assim, no tocante a cinco Pólos de EaD, apenas 3 foram pesquisados nos aspectos dos questionários respondidos e, apenas 2 Pólos de EaD que possuem resultado quanto às desistências dos estudantes com relação ao CPG em EaD da UFSM.

Ainda, passa-se a expor os dados coletados e, as suas respectivas análises, no que tange às defesas realizadas nos anos de 2009 e 2010, na Educação Ambiental na modalidade de EaD.

Foi verificado que no ano de 2009, conforme dados coletados apenas no que diz respeito aos Pólos de São Sepé e Panambi, um total de 12 defesas realizadas. Por outro lado, observou-se que 


\section{Monografias Ambientais}

os assuntos trabalhados nessas monografias dizem respeito às três linhas de pesquisas desta Especialização.

Contrariando os dados do ano anterior, as defesas realizadas no ano de 2010, referem-se a todos os 5 Pólos (Panambi, Cacequi, Agudo, Sapiranga e São Sepé), assim, constatou-se um total de 54 monografias apresentadas no presente ano, no ensino à distância, destacando-se o Sapiranga como pólo de maior número de defesas.

No que confere-se às três linhas de pesquisas deste CPG, concluiu-se, também, que há um certo equilibro quanto às linhas de pesquisas estudadas pelos acadêmicos, resultando em $30 \%$ das defesas em Práticas Educativas, 40\% em Educação, Sociedade e Cultura e, 30\% das defesas foram em relação à Problemas Ambientais.

Objetivando alcançar resultados, foi necessário levar em consideração alguns aspectos no que tange às entrevistas realizadas aos Professores.

De modo geral, apenas 5 Professores participaram. Como justificativa para este fato, podese alegar o acesso, nem sempre suficiente para a devida utilização da internet e suas ferramentas, pois, os questionários foram enviados por e-mail.

De toda sorte, parece claro o fato dos Professores possuírem menos de 5 anos de docência no ensino à distância e, considerarem o curso de conceito muito bom, assim como avaliaram os tutores, atribuindo-lhes o mesmo conceito do curso.

O questionário aplicado aos tutores possui em sua estrutura seis questões, e apenas dois tutores responderam o questionário, assim, foi verificado que $50 \%$ dos tutores já realizaram esta atividade e, que os demais $50 \%$ não haviam realizado tutorias anteriores. Neste contexto, $100 \%$ elucidou que são tutores por um período inferior a um ano. De mesmo modo, $100 \%$ dos entrevistados avaliam esta Especialização, bem como o seu quadro docente, como um curso e seus Professores, merecedores do conceito máximo.

\section{CONCLUSÕES}

O trabalho monográfico, ora apresentado em artigo, trata-se de uma pesquisa com relação a um olhar inédito quanto a Especialização em Educação Ambiental na modalidade de EaD da UFSM, pois investigam-se dados que possam ser capturados com o objetivo de identificar o perfil dos candidatos ao curso, bem como o perfil dos acadêmicos desse CPG.

Desejou-se com esta pesquisa, abordar sobre os cinco Pólos de EaD, do curso supra, dentro do Estado do Rio Grande do Sul, porém, nada obsta que dificuldades existam e, algumas descobertas vão sendo realizadas ao longo do aprofundamento das pesquisas e estudos, chegando a outros resultados, não menos importantes, a posteriori.

Notável é, no entanto, que o número de estudantes mulheres se perfaça face aos números relativos aos estudantes masculinos, pois observou-se, exatamente que foram entrevistadas 134 mulheres e, apenas 57 homens.

$E$, esse fato, pode conceber duas reflexões a respeito. A primeira reflexão está no que tange a preocupação e maior liberdade ou facilidade que as estudantes mulheres encontram na forma de expressarem seus sentimentos, anseios e interesse em integrarem este curso, que exige bastante argumentação e sensibilidades.

É possível afirmar que, independentemente de qualquer situação ou tempo, o indivíduo detentor de direitos sobre o meio ambiente terá, a seu tempo, que cumprir com o seu dever de proteção ambiental e de prevenção de danos ecológicos, vislumbrando um meio ambiente 


\section{Monografias Ambientais}

equilibrado e com qualidade de vida a todas as gerações. Ou, em outras palavras, independentemente do sexo, cor, raça, crença, todos, mais cedo ou mais tarde, se interessarão pela Educação Ambiental, seja ela estudada de maneira formal ou informal.

Entretanto, retornando a idéia anterior, nota-se que todos os 191 alunos(as) investigados possuem acesso facilitado ao computador, e por conseqüência, também possuem acesso a internet, objetos essenciais para a atividade de especialização em EA à distância.

O que se percebeu, através de seus relatos (informações colhidas em segundo momento das entrevistas) é o fato de que muitos nasceram em regiões rurais, embora que a grande maioria afirme ter nascido e vivido sempre em cidades.

Sem surpresa alguma, observou-se que dos 191 estudantes, 56 residem nas cidades-pólos do CPG em Educação Ambiental, contra 135 que residem fora destes pólos. Desde o início deste trabalho, acreditou-se que muitos estudantes seriam residentes das cidades-pólos, mas o interessante é que face aos demais estudantes, esse número se mostrou pequeno.

Uma situação interessante é o fato de que, este curso de Especialização recebe inscrições, à seleção e matrículas, em sua grande maioria por estudantes que exercem atividades remuneradas. $\mathrm{E}$, ainda, a grande maioria desses são professores do ensino fundamental e médio.

No que diz respeito aos dias da semana, conforme análises anteriores, Sapiranga é o pólo em que os estudantes dedicam pelo menos um dia na semana às atividades acadêmicas, igualando-se ao Pólo de Cacequi. Com isso, se demonstram bastante interessados, face ao grupo de estudantes de Agudo.

Com relação ao Pólo de Sapiranga, o mesmo acontece quanto aos turnos disponibilizados para estudos, diferentemente dos pólos de Cacequi e Agudo. Destes, Agudo ainda demonstra maior interesse e dedicação.

Assim, entende-se que é preciso melhorar a comunicação entre o curso e seus alunos(as), buscando evitar algumas dúvidas freqüentes, ou nem tanto, de determinados estudantes que, por outro lado, devem conversar com seus professores entre outros instrutores, visando a mais simples troca de experiências em Educação Ambiental, buscando sanar essas dúvidas mais corriqueiras.

De qualquer sorte, percebe-se o curso como sendo bastante procurado, por homens e mulheres, bem como esses estudantes se demonstram preparados para cumprirem suas missões dentro de um CPG em Educação Ambiental na modalidade de EaD.

Em contrapartida, conforme dados observados e, análises docentes e discentes, os alunos do curso devem dedicar-se mais, interessando-se mais pelos diálogos e conversações, entre outras trocas de saberes, sempre possibilitadas neste CPG, inclusive possibilitadas nos ambientes fora dele.

Ainda, no que tange aos acadêmicos que concluíram o curso, verifica-se que somente no segundo semestre do ano de 2009, foram 12 monografias defendidas entre os Pólos de São Sepé e de Panambi.

$E$, quanto às linhas de pesquisas desta CPG, observa-se um certo equilíbrio entre as temáticas escolhidas pelos estudantes, pois, 5 defesas trataram da primeira linha, Educação, Sociedade e Cultura. Enquanto que, outras 5 defesas trabalharam com os Problemas Ambientais (segunda linha) e, as demais monografias trataram das Práticas Educacionais.

Somente neste ano de 2010, constatou-se um número mais relevante, posto que mais elevado. Isso explica-se no sentido de que foram (somando-se a estas aquelas que ainda serão apresentadas no decorrer do mês de dezembro) realizadas 54 defesas. Estas se referem a todos os cinco pólos pesquisados. Assim, as defesas estão expostas em 19 monografias que trabalharam 


\section{Monografias Ambientais}

REMOA

(Revista Eletrônica do Curso de Especialização em Educação Ambiental da UFSM)

com a primeira linha de pesquisa, outras 14 que se envolveram com os Problemas ambientais e, as demais trataram da terceira linha de pesquisa, ou seja, das Práticas Educacionais.

Acredita-se que com este estudo, foi possível visualizar um perfil da CPG em Educação Ambiental no EaD da UFSM. Neste sentido, foi demonstrado aspectos, antes não observados, analisados e quantificados. Esses aspectos dizem respeito a personalidade do entrevistado, ou seja, foram realizados questionamentos sobre suas atividades, vida, família, desejos, etc.

Assim, visualizou-se que os estudantes, tanto aqueles que participaram da seleção quanto dos que efetivamente cursaram este CPG, almejavam utilizar dos conhecimentos em EA para aplicá-los em sua vida, pessoal e profissional.

Esta pesquisa está aberta (e dá abertura) para outras análises e avaliações sobre muitos outros aspectos relativos a esta Especialização, deixando uma pequena contribuição para, o que pode-se chamar de, um raio-x do curso e de seus envolvidos. Enfim, as portas permanecem abertas.

\section{REFERÊNCIAS BIBLIOGRÁFICAS}

BARRETO, V. Paulo Freire para educadores. São Paulo: Editora Arte \& Ciência, 1998.

FERRARO JÚNIOR, L. A. (Org.). Encontros e Caminhos: formação de educadoras(es) ambientais e coletivos educadores. Brasília: MMA, Diretoria de Educação Ambiental, 2005.

HAETINGER, M. G. Informática na Educação: um olhar criativo. 2.ed. Coleção Criar. 2003.

Lei de no 6938 de agosto de 1981 - Política Nacional do Meio Ambiente. Disponível em: <http://www.jurisambiente.com.br/ambiente/lei3.htm> Acesso em: 16 set. 2010.

O que é a UAB? Disponível em: <http://cead.ufsm.br/moodle/mod/resource/view.php?id=98496>. Acesso em: 3 set. 2010.

Objetivos específicos do Curso de Especialização em Educação Ambiental em EAD da UFSM. Disponível em: <http://www.ufsm.br/educacaoambientaladistancia/>. Acesso em: 3 set. 2010.

Objetivo geral do Curso de Especialização em Educação Ambiental em EAD da UFSM. Disponível em: <http://www.ufsm.br/educacaoambientaladistancia/>. Acesso em: 3 set. 2010.

Perfil do Especialista em Educação Ambiental em EAD da UFSM. Disponível em: <http://www.ufsm.br/educacaoambientaladistancia/>. Acesso em: 3 set. 2010.

Projeto Pedagógico da Especialização em Educação Ambiental da UFSM. Disponível em: <http://www.ufsm.br/educacaoambiental/>. Acesso em: 3 set. 2010.

SCOCUGLIA, A. C. A história da idéias de Paulo Freire e a atual crise de paradigmas. 2.ed. João Pessoa: Editora Universitária, UFPB, 1999.

SEED/MEC. Programa de Formação Continuada Mídias na Educação: módulo gestão integrada de mídias. FNDE.

SEED/MEC. Programa de Formação Continuada Mídias na Educação: módulo introdutório integração de mídias na educação. FNDE.

Universidade Federal de Santa Maria (UFSM). Disponível em: <www.ufsm.br>. Acesso em: 3 set. 2010.

TOLEDO, A. L. (colab.); et. al. VADE MECUM SARAIVA - 9. ed. ampl. e atual. Constituição da República Federativa do Brasil. São Paulo: Editora Saraiva, 2010. 